\title{
Gemcitabine alone or in combination with cisplatin in patients with biliary tract cancer: a comparative multicentre study in Japan
}

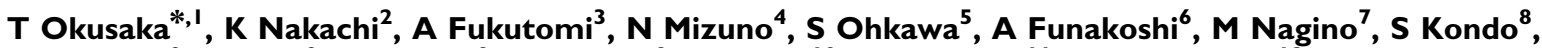 S Nagaoka', J Funai', M Koshiji', Y Nambu', J Furuse ${ }^{10}$, M Miyazaki' ' and Y Nimura' ${ }^{12}$}

'Hepatobiliary and Pancreatic Oncology Division, National Cancer Center Hospital, 5-I-I Tsukiji, Chuo-ku, Tokyo I04-0045, Japan; ${ }^{2}$ Division of Hepatobiliary and Pancreatic Oncology, National Cancer Center Hospital East, Kashiwa, Japan; ${ }^{3}$ Division of Gastrointestinal Oncology, Shizuoka Cancer Center, Shizuoka, Japan; ${ }^{4}$ Department of Gastroenterology, Aichi Cancer Center Hospital, Nagoya, Japan; ${ }^{5}$ Division of Hepatobiliary and Pancreatic Medical Oncology, Kanagawa Cancer Center, Yokohama, Japan; ${ }^{6}$ Division of Gastroenterology, Kyushu Cancer Center, Fukuoka, Japan; ${ }^{7}$ Division of Surgical Oncology, Nagoya University Graduate School of Medicine, Nagoya, Japan; ${ }^{8}$ Department of Surgical Oncology, Hokkaido University Graduate School of Medicine, Sapporo, Japan; ${ }^{9}$ Eli Lilly Japan K.K., Kobe, Japan; ${ }^{10}$ Department of Internal Medicine, Medical Oncology, Kyorin University School of Medicine, Tokyo, Japan; "'Department of General Surgery, Chiba University Graduate School of Medicine, Chiba, Japan; '2 Aichi Cancer Center, Nagoya, Japan

BACKGROUND: A British randomised study of gemcitabine plus cisplatin (GC) combination showed promising results in biliary tract cancer (BTC) patients. In our study, we evaluated the efficacy and safety of this combination compared with gemcitabine alone (G) in Japanese BTC patients.

METHODS: Overall, 84 advanced BTC patients were randomised to either cisplatin $25 \mathrm{mg} \mathrm{m}^{-2}$ plus gemcitabine $1000 \mathrm{mg} \mathrm{m}^{-2}$ on days I, 8 of a 2 I-day cycle (GC-arm), or single-agent gemcitabine $1000 \mathrm{mg} \mathrm{m}^{-2}$ on days I, 8 and I 5 of a 28-day cycle (G-arm). Treatments were repeated for at least 12 weeks until disease progression or unacceptable toxicity occurred, up to a maximum of 48 weeks. RESULTS: A total of 83 patients were included in the analysis. For the GC and G-arms, respectively, the I-year survival rate was 39.0 vs $31.0 \%$, median survival time 11.2 vs 7.7 months, median progression-free survival time 5.8 vs 3.7 months and overall response rate 19.5 vs $11.9 \%$. The most common grade 3 or 4 toxicities (GC-arm/G-arm) were neutropenia (56.1\%/38.1\%), thrombocytopenia (39.0\%/7.1\%), leukopenia (29.3\%/19.0\%), haemoglobin decrease (36.6\%/16.7\%) and $\gamma$-GTP increase (29.3\%/35.7\%).

CONCLUSIONS: Gemcitabine plus cisplatin combination therapy was found to be effective and well tolerated, suggesting that it could also be a standard regimen for Japanese patients.

British Journal of Cancer (2010) 1 03, 469-474. doi:10.1038/sj.bjc.6605779 www.bjcancer.com

Published online 13 July 2010

(c) 2010 Cancer Research UK

Keywords: combination chemotherapy; gemcitabine; cisplatin; biliary tract cancer

Although biliary tract cancer (BTC) is a rare type of cancer throughout the world, it is more prevalent in East Asia and Latin America than in other countries (Matsuda and Marugame, 2007; Randi et al, 2009). According to 'Demographic Statistics in Japan (2009)' (compiled by the Statistics and Information Department, Minister's Secretariat, Ministry of Health, Labour, and Welfare (MHLW)), the number of deaths due to BTC was 17311 in 2007, making this cancer the sixth leading cause of cancer death in Japan.

Despite great progress in diagnostic imaging, most cases of BTC are diagnosed as advanced and inoperable. Even if the tumour is not locally advanced, the primary tumour site is often contiguous with vital organs such as the liver, pancreas, or duodenum, or with major vessels such as the portal vein or hepatic artery. This

*Correspondence: Dr T Okusaka; E-mail: tokusaka@ncc.go.jp Results were presented in part at the 45th American Society of Clinical Oncology Annual Meeting, May 2009, Orlando, FL (USA).

Received 2 March 20I0; revised 3 June 20I0; accepted II June 20I0; published online 13 July 2010 anatomical peculiarity precludes resection of tumours in many cases. Furthermore, even if curative-intent surgical resection is performed, the cancer often relapses due to its invasive nature and its anatomical characteristics.

Systemic chemotherapy is usually indicated for patients with unresectable, advanced BTC or for those who have relapsed after operation; however, no standard treatment has yet been established for such patients. Gemcitabine hydrochloride is a deoxycytidine derivative that inhibits DNA elongation through intracellular phosphorylation of ribonucleotide reductase. In Japan, a single-arm Phase II study in patients with unresectable BTC confirmed that gemcitabine monotherapy had moderate efficacy and manageable toxicity, both of which were comparable with approved treatments for other cancers (Okusaka et al, 2006).

As gemcitabine had also been found to exhibit synergistic effects on cytotoxic activity in vitro and in vivo when combined with cisplatin (Peters et al, 1995; Bergman et al, 1996), clinical studies were conducted in various cancers with this combination. Results from these studies eventually led to use of the gemcitabine plus cisplatin (GC) combination as one of the standard treatments for non-small cell lung cancer and bladder cancer. 
The combination of GC has also been studied by many researchers for the treatment of BTC (Park et al, 2006; Eckel and Schmid, 2007; Pasetto et al, 2007; Lee et al, 2008). So far, the largest randomised Phase III study has been the recent UK ABC-02 study, in which the efficacy and safety of gemcitabine $1000 \mathrm{mg} \mathrm{m}^{-2}$ alone $v s$ the combination of gemcitabine $1000 \mathrm{mg} \mathrm{m}^{-2}$ plus cisplatin $25 \mathrm{mg} \mathrm{m}^{-2}$ was evaluated by British research groups (Cancer Research UK and University College London). That study was initiated as a randomised phase II study with gemcitabine alone $v s$ GC (UK ABC-01 study) and then was expanded to a phase III study (ABC-02 study) (Valle et al, 2009a, b).

Our study was planned to follow-up on an earlier study of gemcitabine monotherapy conducted in Japanese BTC patients (Okusaka et al, 2006). Given the encouraging results from the UK ABC-01 study, we conducted this study to (1) evaluate both gemcitabine monotherapy and the GC combination in Japanese BTC patients, and (2) determine whether benefits similar to those observed in the UK study could be obtained for the combination regimen.

The primary objective of the study was to compare the 1-year survival rate in patients with BTC who received one of these two therapies. The secondary objectives included response rate, progression-free survival (PFS) and assessment of safety.

\section{MATERIALS AND METHODS}

\section{Study design}

This was a multicentre, randomised phase II study to evaluate the efficacy and safety of GC combination compared with single-agent gemcitabine in chemotherapy-naive patients with locally advanced or metastatic BTC. Patients were randomised to either single-agent gemcitabine $1000 \mathrm{mg} \mathrm{m}^{-2}$ on days 1,8 and 15 of a 28 -day cycle (G-arm) or cisplatin $25 \mathrm{mg} \mathrm{m}^{-2}$ followed by gemcitabine $1000 \mathrm{mg} \mathrm{m}^{-2}$ on days 1, 8 of a 21-day cycle (GC-arm). Randomisation was stratified by primary site (gallbladder cancer or other BTC) and the presence or absence of primary tumour.

\section{Eligibility criteria}

Eligible patients met the following criteria: histologically confirmed unresectable locally advanced or metastatic cancer of the biliary tract; no history of earlier chemotherapy; performance status of 0 or 1; a life expectancy of at least 3 months; at least 20 years of age at the time of study entry; adequate function of major organs (haemoglobin $\geqslant 10 \mathrm{~g}$ per $100 \mathrm{ml}$, white blood cells $\geqslant 3000 / \mathrm{mm}^{3}$, neutrophils $\geqslant 1500 / \mathrm{mm}^{3}$, platelets $\geqslant 100000 / \mathrm{mm} 3$, AST/ALT/ALP $\leqslant 3$ times upper limit of normal (ULN), total bilirubin $\leqslant 2$ times ULN, $\leqslant 3$ times ULN for patients with obstructive jaundice or metastases to the liver, serum creatinine $\leqslant 1.5$ times ULN, creatinine clearance or 24 -h creatinine clearance $\geqslant 45 \mathrm{ml} \mathrm{min}^{-1}$ ).

This study followed the ethical principles that have their origins in the Declaration of Helsinki, and was conducted in accordance with the protocol, the 'ordinance on Good Clinical Practice' and related regulations. Written informed consent was obtained from all patients who were considered eligible for participation in this study before enrolment. The Efficacy and Safety Evaluation Committee, an independent review board, was consulted if any efficacy and safety issues arose in the study.

\section{Study treatment}

The assigned treatment was given for a minimum of 12 weeks (at least four cycles in the GC-arm and three cycles in the G-arm) and continued to a maximum of 48 weeks (up to 16 cycles in the GC-arm and up to 12 cycles in the G-arm), unless disease progression (PD) was evident, an intolerable adverse event occurred or the patient was required to withdraw from the study.

\section{Efficacy and safety assessment}

All patients who received at least 1 dose of the study drug were included in the efficacy and safety assessment. Response rate was evaluated according to the Response Evaluation Criteria in Solid Tumors. Evaluation of tumours after patient randomisation was performed every 6 weeks until PD. Adverse events were graded according to the Common Terminology Criteria for Adverse Events, version 3.0 (CTCAE v3.0).

\section{Statistical design and analysis}

The sample size was calculated by the selection method of Simon (Simon et al, 1985), which is based on the proposition that GC combination therapy is selected if the 1-year survival rate for the GC-arm is higher than that for the gemcitabine arm. We assumed a 1 -year survival rate of $25 \%$ for the G-arm and $35 \%$ for GC-arm (Okusaka et al, 2006; Park et al, 2006). With these assumptions, 30 patients per arm were needed to appropriately select the combination therapy with a probability of $\geqslant 80 \%$. To optimise safety and efficacy information, the sample size was set to 42 patients per arm.

The Kaplan-Meier method was used to estimate 1-year survival (primary outcome), PFS and 6-month PFS rates (secondary outcomes) for each treatment arm; 95\% confidence intervals (CIs) were calculated. A Cox proportional hazards model was used to calculate the hazard ratio, $95 \% \mathrm{CI}$ and its two-tailed $P$-value. Fisher's exact test was used to compare the patient characteristics, response and disease control rates, and toxicities between the two treatment arms. The exact CIs were calculated based on binomial distributions.

\section{RESULTS}

\section{Patients}

This study was carried out from September 2006 to October 2008 at nine study centres in Japan. Eighty-four patients were randomised to either gemcitabine monotherapy (G-arm) or GC combination (GC-arm). One patient assigned to the GC-arm was not treated because the general condition of the patient deteriorated before study treatment. All of the remaining 83 patients, 41 in the GC-arm and 42 in the G-arm, received at least 1 dose of study treatment. Efficacy and safety were evaluated for each of these 83 patients (Figure 1). Demographic variables (Table 1) were well balanced between the two treatment arms, except for patients with ampullary carcinoma (4 in GC-arm, 0 in G-arm).

\section{Drug exposure and duration of the treatments}

A total of 247 (median 6.0) and 203 (median 4.0) cycles were administered in the GC-arm and G-arm, respectively. Relative dose intensities were $78.9 \%$ for gemcitabine and $79.0 \%$ for cisplatin in the GC-arm, and $87.4 \%$ for gemcitabine in the G-arm. Three patients in the GC-arm and two patients in the G-arm completed 48 weeks treatment.

\section{Efficacy}

A total of 83 patients were evaluable for tumour response according to the protocol, 41 in the GC-arm and 42 in the G-arm. No complete tumour responses were observed. In total, eight patients in the GC-arm had a partial response (PR) compared with five patients in the G-arm (PR 19.5 vs 11.9\%). In addition, 


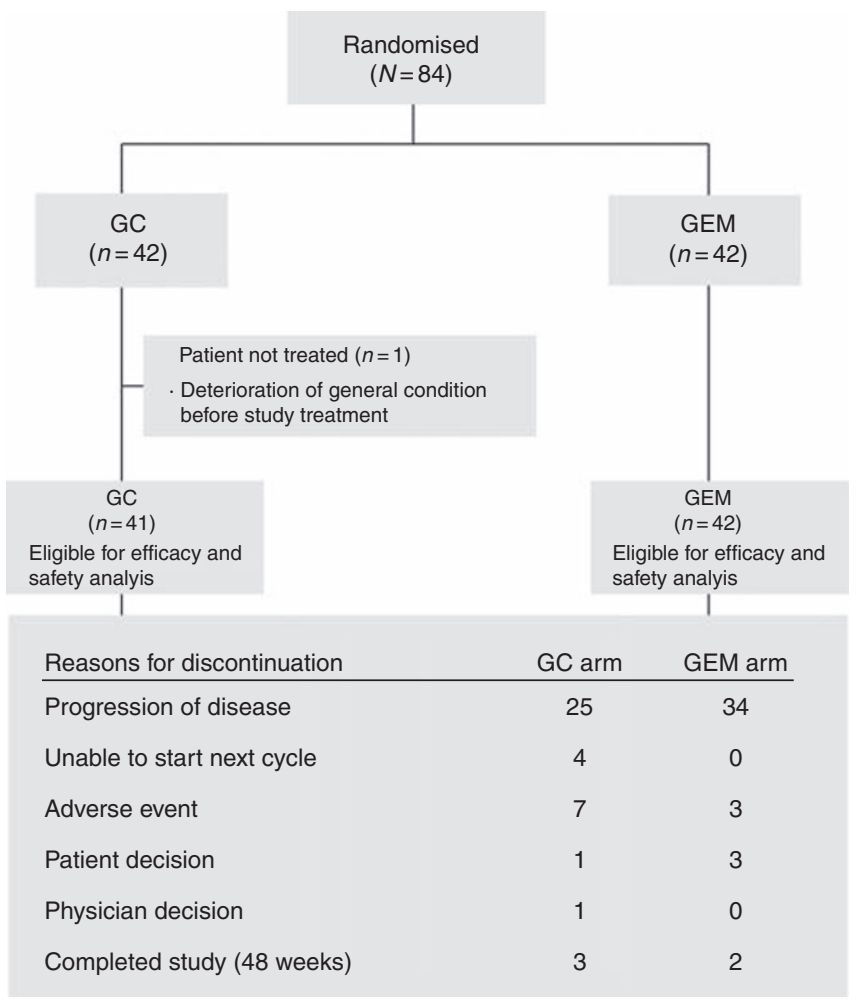

Figure I CONSORT diagram. Disposition of patients. GC= gemcitabine-cisplatin combination; GEM = gemcitabine alone.

20 patients had stable disease in the GC-arm vs 16 patients in the G-arm (SD 48.8 vs 38.1\%). The disease control rate (CR + PR + SD) was $68.3 \%$ (95\% CI: $51.9,81.9)$ vs $50.0 \%$ (95\% CI: $34.2,65.8)$ in favour of the combination therapy. The 1-year survival rate $(39.0$ vs $31.0 \%)$, median survival time (11.2 months $v s 7.7$ months) and median PFS (5.8 months $v s 3.7$ months) were better for the GC-arm vs G-arm (Figure 2). The hazard ratio between the GC and G-arms was 0.69 (95\% CI: $0.42,1.13)$ for overall survival (OS) and 0.66 (95\% CI: $0.41,1.05$ ) for PFS (Table 2).

As shown in Table 3, the prognosis for patients with gallbladder cancer was worse than that for patients with non-gallbladder cancer; however, the median survival times were longer with the GC combination in gallbladder cancer patients (9.1 months $v s 6.7$ months), as well as in patients with non-gallbladder cancer (13.0 months $v s 8.0$ months). The prognosis for patients with primary tumours was worse than that for patients without primary tumours; however, the GC therapy showed longer median survival time in both patient subgroups (9.4 months vs 7.4 months in the patients with primary tumours, 16.1 months $v s 12.7$ months in the patients without primary tumours).

\section{Safety}

All adverse events observed in this study were predictable and manageable based on the safety profile of GC. As shown in Table 4, the most common grade 3 or higher adverse events $(\geqslant 25 \%)$ were neutropenia $(56.1 \%)$, thrombocytopenia $(39.0 \%)$, haemoglobin decrease (36.6\%), RBC decrease (34.1\%), leukopenia (29.3\%) and $\gamma$-GTP increase $(29.3 \%)$ in the GC-arm, and neutropenia $(38.1 \%)$ and $\gamma$-GTP increase (35.7\%) in the G-arm. The incidence of haematotoxicity was higher in the GC-arm; grade 3 or more serious C-reactive protein increase was detected only in the monotherapy arm.
Table I Patient characteristics

\begin{tabular}{|c|c|c|c|}
\hline Characteristic & $\begin{array}{c}\text { GC }(N=4 I) \\
n(\%)\end{array}$ & $\begin{array}{c}\text { GEM }(N=42) \\
n(\%)\end{array}$ & $P$-value \\
\hline \multicolumn{4}{|l|}{ Gender } \\
\hline Male & $18(43.9)$ & $21(50.0)$ & \multirow[t]{2}{*}{0.662} \\
\hline Female & $23(56.1)$ & $21(50.0)$ & \\
\hline \multicolumn{4}{|l|}{ Age (year) } \\
\hline Median & 65.0 & 66.5 & \multirow[t]{2}{*}{$0.0812^{\mathrm{a}}$} \\
\hline Range & $43-80$ & $49-78$ & \\
\hline \multicolumn{4}{|l|}{ PS } \\
\hline 0 & $34(82.9)$ & $28(66.7)$ & \multirow[t]{2}{*}{0.129} \\
\hline I & $7(17.1)$ & $14(33.3)$ & \\
\hline \multicolumn{4}{|l|}{ Primary tumour sites } \\
\hline Extraheptic bile duct & $8(19.5)$ & II (26.2) & \multirow[t]{4}{*}{0.239} \\
\hline Intraheptic bile duct & $14(34.1)$ & $14(33.3)$ & \\
\hline Gallbladder & $15(36.6)$ & $17(40.5)$ & \\
\hline Ampulla & $4(9.8)$ & $0(0.0)$ & \\
\hline \multicolumn{4}{|l|}{ Metastatic sites } \\
\hline Liver & $22(53.7)$ & $20(47.6)$ & 0.663 \\
\hline Regional lymph nodes & $23(56.1)$ & $28(66.7)$ & 0.372 \\
\hline Distant lymph nodes & $19(46.3)$ & $18(42.9)$ & 0.827 \\
\hline Lung & $8(19.5)$ & $7(16.7)$ & 0.782 \\
\hline Peritoneum & $7(17.1)$ & $7(16.7)$ & 1.000 \\
\hline Bone & $0(0.0)$ & I (2.4) & 1.000 \\
\hline Others & $3(7.3)$ & $3(7.1)$ & 1.000 \\
\hline \multicolumn{4}{|l|}{ Initial onset or recurrence } \\
\hline Initial onset & $30(73.2)$ & $32(76.2)$ & \multirow[t]{2}{*}{0.804} \\
\hline Recurrence after surgery & II (26.8) & $10(23.8)$ & \\
\hline \multicolumn{4}{|l|}{ Histological type } \\
\hline Adenocarcinoma & $39(95.1)$ & $41(97.6)$ & \multirow{2}{*}{0.616} \\
\hline Adenosquamous cancer & $2(4.9)$ & I (2.4) & \\
\hline \multicolumn{4}{|c|}{ Disease stage (gallbladder cancer, extrahepatic bile duct cancer, ampulla cancer) } \\
\hline IIA & $0(0.0)$ & $0(0.0)$ & \multirow[t]{5}{*}{1.000} \\
\hline$\| B$ & $3(7.3)^{b}$ & $2(4.8)^{b}$ & \\
\hline III & $2(4.9)$ & $2(4.8)$ & \\
\hline IV & $16(39.0)$ & $17(40.5)$ & \\
\hline Recurrence after surgery & $6(14.6)$ & $7(16.7)$ & \\
\hline \multicolumn{4}{|c|}{ Disease stage (intrahepatic bile duct cancer) } \\
\hline II & $0(0.0)$ & I $(2.4)^{\mathrm{b}}$ & \multirow[t]{6}{*}{0.389} \\
\hline IIIA & $0(0.0)$ & I (2.4) & \\
\hline IIIB & $0(0.0)$ & $0(0.0)$ & \\
\hline IIIC & $0(0.0)$ & $2(4.8)$ & \\
\hline IV & $9(22.0)$ & $7(16.7)$ & \\
\hline Recurrence after surgery & $5(12.2)$ & $3(7.1)$ & \\
\hline \multicolumn{4}{|l|}{ Biliary drainage } \\
\hline No & $25(61.0)$ & $24(57.1)$ & \multirow[t]{2}{*}{0.824} \\
\hline Yes & $16(39.0)$ & $18(42.9)$ & \\
\hline \multicolumn{4}{|l|}{ Previous therapy } \\
\hline No & $30(73.2)$ & $28(66.7)$ & \multirow[t]{4}{*}{0.855} \\
\hline Surgery & II (26.8) & $12(28.6)$ & \\
\hline Radiotherapy & $0(0.0)$ & I (2.4) & \\
\hline Surgery and radiotherapy & $0(0.0)$ & I (2.4) & \\
\hline
\end{tabular}

Abbreviations: $G C=$ gemcitabine and cisplatin; $G E M=$ gemcitabine; $P S=$ perfor-

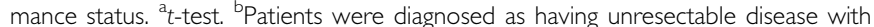
marked regional node metastases involving the proper hepatic artery and/or main portal vein

There were no treatment related deaths. Most of the patients recovered from the above adverse events by reducing or discontinuing the study treatment. 


\section{Post-study chemotherapy}

Thirty patients in the GC-arm received post-study chemotherapy including S-1, tegaful/gimeracil/oteracil potassium (19 patients), gemcitabine (10 patients) and tegaful/uracil (1 patient). In the
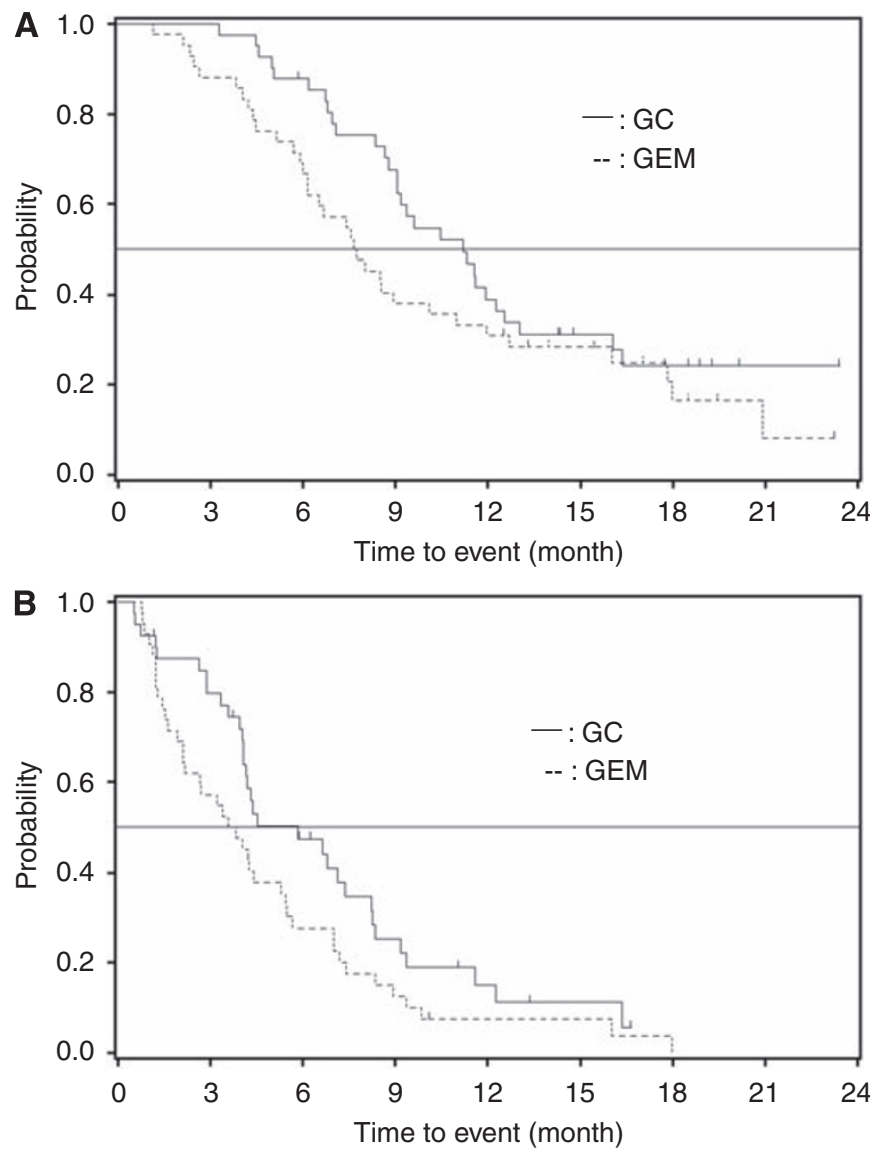

Figure 2 Kaplan-Meier curve of overall survival and progression-free survival. (A) Overall survival. (B) Progression-free survival. GC = gemcitabine-cisplatin combination; GEM = gemcitabine alone; $\mathrm{Cl}=$ confidence interval.
G-arm, 33 patients received post-study chemotherapy including S-1 (20 patients), gemcitabine (11 patients), cisplatin/fluorouracil (1 patient) and doxorubicin/tegaful/uracil (1 patient).

\section{DISCUSSION}

Although this study (BT22 study) showed that gemcitabine monotherapy and the GC combination were both active in Japanese patients with advanced BTC, a superior benefit was obtained with the combination treatment. In the GC/G-arms, the 1-year survival rate was $39.0 \% / 31.0 \%$, median survival time was 11.2/7.7 months and median PFS time was 5.8/3.7 months (Table 2).

The UK ABC-02 study, which was conducted with the same dose and regimen as this study (Valle et al, 2009b), showed a similar benefit for the GC combination. The respective median survival/ PFS times in that study were $11.7 / 8.5$ months in their GC-arm, and 8.2/6.5 months in their G-arm.

The hazard ratios reported in the ABC-02 study for OS $(0.68$, $95 \%$ CI: $0.53,0.86)$ and PFS $(0.70,95 \%$ CI: $0.56,0.88)$ compared well with the respective values from our study: 0.69 (95\% CI: 0.42 , 1.13 ) and 0.66 (95\% CI: $0.41,1.05)$. As the number of patients was based on Simon's selection method (Simon et al, 1985), this study was not designed to compare and identify statistical significant differences between the two treatment arms. These hazard ratios

Table 3 Overall survival time by stratification factor

\begin{tabular}{|c|c|c|c|}
\hline $\begin{array}{l}\text { Median survival } \\
\text { time (months) } \\
(95 \% \mathrm{Cl})\end{array}$ & $\mathbf{G C}(N=4 !)$ & $\operatorname{GEM}(N=42)$ & P-value \\
\hline \multicolumn{4}{|l|}{ Tumour site } \\
\hline Gallbladder & $9.1(6.9,11.6)$ & $6.7(4.2,11.0)$ & 0.675 \\
\hline Non-gallbladder & $13.0(9.2, * * *)$ & $8.0(6.1,16.0)$ & 0.110 \\
\hline \multicolumn{4}{|l|}{ Primary tumour } \\
\hline Presence of primary tumour & $9.4(8.7,11.6)$ & $7.4(5.9,8.5)$ & 0.253 \\
\hline Absence of primary tumour & $16.1(12.3, * * *)$ & $12.7(6.5, * * *)$ & 0.389 \\
\hline
\end{tabular}

Abbreviations: $\mathrm{GC}=$ gemcitabine and cisplatin; $\mathrm{GEM}=$ gemcitabine; $\mathrm{Cl}=$ confidence interval. *****enotes upper limits are not available.

Table 2 Summary of time-to-event end points: overall response and survival

\begin{tabular}{|c|c|c|c|}
\hline & $\begin{array}{c}\text { GC }(N=4 I) \\
n(\%)\end{array}$ & $\begin{array}{c}\text { GEM }(N=42) \\
n(\%)\end{array}$ & $P$-value \\
\hline \multicolumn{4}{|l|}{ Overall response rate } \\
\hline Partial response (PR) & $8(19.5)$ & $5(11.9)$ & \\
\hline Stable disease (SD) & $20(48.8)$ & $16(38.1)$ & \\
\hline Progressive disease (PD) & $9(22.0)$ & $17(40.5)$ & \\
\hline Not evaluable (NE) & $4(9.8)$ & $4(9.5)$ & \\
\hline \multicolumn{4}{|l|}{ Overall sunvival } \\
\hline I-year survival rate $(95 \% \mathrm{Cl})$ & $39.0 \%(23.7,54.4)$ & $31.0 \%(17.0,44.9)$ & \\
\hline Median survival time $(95 \% \mathrm{Cl})$ & I1.2 months (9.1, 12.5) & 7.7 months $(6.1,11.0)$ & \\
\hline Hazard ratio $(95 \% \mathrm{Cl})$ & \multicolumn{2}{|c|}{$0.69(95 \% \mathrm{Cl}: 0.42,1.13)$} & 0.139 \\
\hline \multicolumn{4}{|l|}{ Progression-free survival (PFS) } \\
\hline
\end{tabular}

Abbreviations: $\mathrm{GC}=$ gemcitabine and cisplatin; $\mathrm{GEM}=$ gemcitabine; $\mathrm{Cl}=$ confidence interval. 
Table 4 Summary of maximum toxicity grades ${ }^{\mathrm{a}}$ (incidence $\geqslant 30 \%$ )

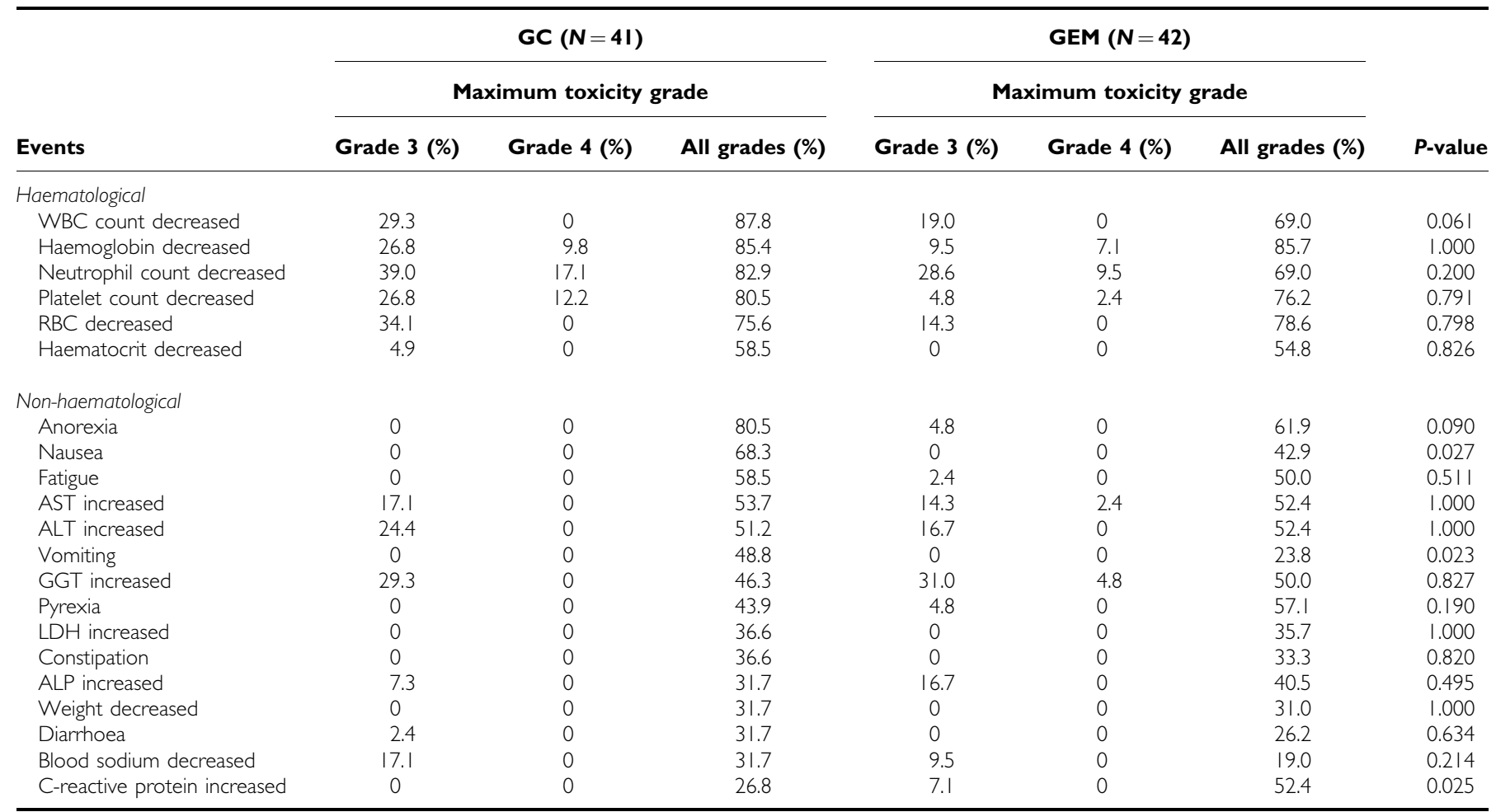

Abbreviations: $\mathrm{ALP}=$ alkaline phosphatase; $\mathrm{ALT}=$ alanine aminotransferase; $\mathrm{AST}=$ aspartate aminotransferase; $\mathrm{GC}=$ gemcitabine and cisplatin; $\mathrm{GEM}=$ gemcitabine; $\mathrm{GGT}=$ $\gamma$-glutamyltransferase; $\mathrm{LDH}=$ lactate dehydrogenase; $\mathrm{RBC}=$ red blood cell; $\mathrm{WBC}=$ white blood cell. ${ }^{\mathrm{a}}$ Events were graded according to $\mathrm{CTCAE}$ v3.0.

strongly suggest that the GC combination has superior benefit compared with single-agent gemcitabine, even though there were no statistical significant differences in survival and PFS between the two arms in our study.

Although there have been many single-arm Phase II studies of the GC combination for BTC (Thongprasert et al, 2005; Kim et al, 2006; Charoentum et al, 2007; Meyerhardt et al, 2008; Valle et al, 2009a), these results have never been distilled to one fixed dose and regimen of GC. Many previous studies of GC combination reported relatively higher response rates, but with more serious treatment-related adverse events (Thongprasert et al, 2005; Kim et al, 2006; Charoentum et al, 2007; Meyerhardt et al, 2008). In the phase II study conducted by Thongprasert et al (2005), $17.85 \%$ of the patients who were treated with the GC combination required dose reduction, and in another Phase II study recently conducted by Meyerhardt et al (2008), dose reductions and study withdrawals were required for $50 \%$ of the patients who received the combination therapy. In our study, we also observed more frequent adverse events with the doublet (Table 4). However, as shown in Figure 1, only seven patients (17\%) discontinued from the study because of adverse events and four patients $(9.7 \%)$ required dose adjustments in the GC-arm.

Overall, the toxicity observed in this study was manageable. Although interstitial pneumonia was detected in one patient from each of the arms, both patients recovered with appropriate treatment. One grade 3 renal failure and one grade 2 peripheral neuropathy were observed in GC-arm, in line with similar events seen in previous studies of the GC combination (Thongprasert et al, 2005; Kim et al, 2006; Charoentum et al, 2007; Meyerhardt et al, 2008; Valle et al, 2009a). It is to be noted that despite the higher incidence of haematotoxicity in patients receiving the combination therapy, drug-caused myelosuppression did not result in febrile neutropenia or bleeding. Grade 3 or greater increases in C-reactive protein were observed only in the gemcitabine monotherapy-arm, also suggesting that the combination therapy did not increase neutropenic infections.

In this study, we stratified patients into those with gallbladder cancer and those with other BTCs. Gallbladder cancer has been reported to have a different biological behaviour (Kim et al, 2006; Doval et al, 2004; Jarnagin et al, 2006); furthermore, a pooled analysis by Eckel and Schmid (2007) revealed a higher response rate to chemotherapy and shorter OS for gallbladder cancer compared with other BTCs. As shown in Table 3, patients with gallbladder cancer showed worse survival than patients with other BTCs, this being consistent with previous reports (Eckel and Schmid, 2007; Wagner et al, 2009). It is important to note that median survival times were longer with the GC combination in patients with gallbladder cancer (9.1 months vs 6.7 months), as well as in patients with non-gallbladder cancer (13.0 months vs 8.0 months), suggesting that the combination therapy has greater benefit than monotherapy in gallbladder cancer and other BTC patients.

Another stratification factor used for this study was the presence or absence of a primary tumour, not a commonly used stratification factor in clinical trials for advanced BTC. Locally advanced or metastatic cancer, the stratification factor used in the UK ABC-01 and UK ABC-02 studies, is more commonly used, as both of these have been shown to affect OS in advanced BTC (Park et al, 2009). However, considering the importance of surgical resection of the primary tumour, we decided to use this as a stratification factor for patients in this study. As shown in Table 3, patients with primary tumours showed remarkably worse survival than patients without primary tumours. However, because of the limited number of patients in our subanalyses, the results should be viewed with caution, and the usefulness of this prognostic factor should be evaluated in future studies. We will continue our efforts 
474

in collaboration with the UK ABC-02 study group to identify prognostic factors in a larger population, which may significantly affect clinical studies in BTC.

Despite the heterogeneous nature of BTC and the ethnic differences reported for this tumour type (Goodman and Yamamoto, 2007; Aljiffry et al, 2009), the outcomes from this study showed striking similarity with the large-scale phase III study (UK ABC-02) results. This suggests that cisplatin $25 \mathrm{mg} \mathrm{m}^{-2}$ plus gemcitabine $1000 \mathrm{mg} \mathrm{m}^{-2}$ on days 1 and 8 of a 21-day cycle would be beneficial in the treatment of advanced BTC.

\section{REFERENCES}

Aljiffry M, Walsh MJ, Molinari M (2009) Advances in diagnosis, treatment and palliation of cholangiocarcinoma: 1990-2009. World J Gastroenterol 15: $4240-4262$

Bergman AM, Ruiz van Haperen VW, Veerman G, Kuiper CM, Peters GJ (1996) Synergistic interaction between cisplatin and gemcitabine in vitro. Clin Cancer Res 2: $521-530$

Charoentum C, Thongprasert S, Chewaskulyong B, Munprakan S (2007) Experience with gemcitabine and cisplatin in the therapy of inoperable and metastatic cholangiocarcinoma. World J Gastroenterol 13: 2852-2854

Doval DC, Sekhon JS, Gupta SK, Fuloria J, Shukla VK, Gupta S, Awasthy BS (2004) A phase II study of gemcitabine and cisplatin in chemotherapynaive, unresectable gall bladder cancer. Br J Cancer 90: 1516-1520

Eckel F, Schmid RM (2007) Chemotherapy in advanced biliary tract carcinoma: a pooled analysis of clinical trials. Br J Cancer 96: 896-902

Goodman MT, Yamamoto J (2007) Descriptive study of gallbladder, extrahepatic bile duct, and ampullary cancers in the United States, 1997 - 2002. Cancer Causes Control 18: 415-422

Jarnagin WR, Klimstra DS, Hezel M, Gonen M, Fong Y, Roggin K, Cymes K, DeMatteo RP, D'Angelica M, Blumgart LH, Singh B (2006) Differential cell cycle-regulatory protein expression in biliary tract adenocarcinoma: correlation with anatomic site, pathologic variables, and clinical outcome. J Clin Oncol 24: $1152-1160$

Kim ST, Park JO, Lee J, Lee KT, Lee JK, Choi SH, Heo JS, Park YS, Kang WK, Park K (2006) A Phase II study of gemcitabine and cisplatin in advanced biliary tract cancer. Cancer 106: $1339-1346$

Lee J, Kim TY, Lee MA, Ahn MJ, Kim HK, Lim HY, Lee NS, Park BJ, Kim JS (2008) Phase II trial of gemcitabine combined with cisplatin in patients with inoperable biliary tract carcinomas. Cancer Chemother Pharmacol 61: 47-52

Matsuda T, Marugame T (2007) International comparisons of cumulative risk of gallbladder cancer and other biliary tract cancer, from Cancer Incidence in Five Continents Vol. VIII Jpn J Clin Oncol 37: 74-75

Meyerhardt JA, Zhu AX, Stuart K, Ryan DP, Blaszkowsky L, Lehman N, Earle CC, Kulke MH, Bhargava P, Fuchs CS (2008) Phase-II study of gemcitabine and cisplatin in patients with metastatic biliary and gallbladder cancer. Dig Dis Sci 53: $564-570$

Okusaka T, Ishii H, Funakoshi A, Yamao K, Ohkawa S, Saito S, Saito H, Tsuyuguchi T (2006) Phase II study of single-agent gemcitabine in patients with advanced biliary tract cancer. Cancer Chemother Pharmacol 57: $647-653$

Park BK, Kim YJ, Park JY, Bang S, Park SW, Chung JB, Kim KS, Choi JS, Lee WJ, Song SY (2006) Phase II study of gemcitabine and

\section{ACKNOWLEDGEMENTS}

We thank all the patients participated in this study, their families, the investigators and the study site personnel. This study was supported by Eli Lilly Japan K.K.

\section{Conflict of interest}

TO, KN, NM, SO, SK and JF have received honoraria, and YN, MK, JF and SN are employed by Eli Lilly Japan. cisplatin in advanced biliary tract cancer. J Gastroenterol Hepatol 21: $999-1003$

Park I, Lee JL, Ryu MH, Kim TW, Sook Lee S, Hyun Park D, Soo Lee S, Wan Seo D, Koo Lee S, Kim MH (2009) Prognostic factors and predictive model in patients with advanced biliary tract adenocarcinoma receiving first-line palliative chemotherapy. Cancer 115: 4148-4155

Pasetto LM, D'Andrea MR, Falci C, Monfardini S (2007) Gemcitabine in advanced biliary tract cancers. Crit Rev in Oncol Hematol 61: 230-242

Peters GJ, Bergman AM, Ruiz van Haperen VW, Veerman G, Kuiper CM, Braakhuis BJ (1995) Interaction between cisplatin and gemcitabine in vitro and in vivo. Semin Oncol 22(4 Suppl 11): $72-79$

Randi G, Malvezzi M, Levi F, Ferlay J, Negri E, Franceschi S, La Vecchia C (2009) Epidemiology of biliary tract cancers: an update. Ann Oncol 20: $146-159$

Simon R, Wittes RE, Ellenberg SS (1985) Randomized phase II clinical trials. Cancer Treat Rep 69: 1375-1381

Thongprasert S, Napapan S, Charoentum C, Moonprakan S (2005) Phase II study of gemcitabine and cisplatin as first-line chemotherapy in inoperable biliary tract carcinoma. Ann Oncol 16: 279-281

Valle JW, Wasan H, Johnson P, Jones E, Dixon L, Swindell R, Baka S, Maraveyas A, Corrie P, Falk S, Gollins S, Lofts F, Evans L, Meyer T, Anthoney A, Iveson T, Highley M, Osborne R, Bridgewater J (2009a) Gemcitabine alone or in combination with cisplatin in patients with advanced or metastatic cholangiocarcinomas or other biliary tract tumours: a multicentre randomised phase II study - The UK ABC-01 Study. Br J Cancer 101: 621-627

Valle JW, Wasan HS, Palmer DD, Cunningham D, Anthoney DA, Maraveyas A, Hughes SK, Roughton M, Bridgewater JA (2009b) Gemcitabine with or without cisplatin in patients with advanced or metastatic biliary tract cancer (ABC): Results of a multicenter, randomized phase III trial (the UK ABC-02 trial). J Clin Oncol 27: 15s (Suppl; abstract 4503)(Recently the results of this study were published as follows: Valle J, Wasan H, Palmer DH, Cunningham D, Anthoney A, Maraveyas A, Madhusudan S, Iveson T, Hughes S, Pereira SP, Roughton $\mathrm{M}$, Bridgewater J; ABC-02 Trial Investigators (2010) Cisplatin plus gemcitabine versus gemcitabine for biliary tract cancer. $N$ Engl J Med 362: $1273-1281$ )

Wagner AD, Buechner-Steudel P, Moehler M, Schmalenberg H, Behrens R, Fahlke J, Wein A, Behl S, Kuss O, Kleber G, Fleig WE (2009) Gemcitabine, oxaliplatin and 5-FU in advanced bile duct and gallbladder carcinoma: two parallel, multicentre phase-II trials. Br J Cancer 101: 1846-1852 